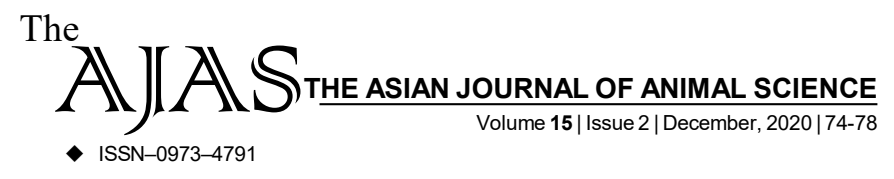

\title{
Soy milk as an innovative and cost effective milk replacer for rearing of calves
}

Biju Chacko and V. Fahmida

Author for Corresponding -

\section{Biju Chacko}

Department of Animal Nutrition,

College of Veterinary and Animal

Sciences, Pookode, Wayanad

(Kerala) India

Email: bijuchacko@kvasu.ac.in
KEY WORDS...... Soy Milk, Innovative, Cost effective milk replacer

HOW TO CITE THIS ARTICLE - Chacko, Biju and Fahmida, V. (2020). Soy milk as an innovative and cost effective milk replacer for rearing of calves. Asian J. Animal Sci., 15(1): 74-78.DOI:10.15740/HAS/ TAJAS/15.2/74-78.Copyright@2020:HindAgri-Horticultural Society.

ARTICLE CHRONICLE - Received : 30.07.2020; Accepted : 14.11.2020 